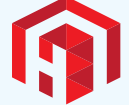 Heighten Science \\ P U B L I C I T I O N S Corporation \\ ISSN}

2576-9537
*Address for Correspondence: Mohamed Abdelhamid, Surgery Department, Faculty of Medicine, Beni Suef, Egypt,

Tel: 00201062531899;

Email: mohamedsalah_2000@hotmail.com

Submitted: 09 November 2018

Approved: 19 November 2018

Published: 20 November 2018

Copyright: (c) 2018 Abdelhamid M, et al. This is an open access article distributed under the Creative Commons Attribution License, which permits unrestricted use, distribution, and reproduction in any medium, provided the original work is properly cited

Keywords: Left colonic emergencies; diverticulitis; Left colon cancer

Check for updates
Research Article

\section{Emergency laparoscopic left sided colonic resection with primary anastomosis: Feasibility and Safety}

\author{
Mohamed Abdelhamid ${ }^{1 *}$, AM Rashad', MA Negida², AZ Garib ${ }^{3}$, \\ SS Soliman ${ }^{4}$ and TM EL Gaabary ${ }^{4}$
}

'Surgery Department, Faculty of Medicine, Beni Suef, Egypt

${ }^{2}$ Surgery Department, Faculty of Medicine, Kasr El Aini, Egypt

${ }^{3}$ Surgery Department, October $6^{\text {th }}$ Faculty of Medicine, Giza, Egypt

${ }^{4}$ Surgery Department, Faculty of Medicine, Fayoum Egypt 
The surgical management of left-sided large bowel emergency patients still remains controversial. There has been an increasing trend towards primary reconstruction surgery, yet the main dilemma remains about the appropriate patient selection for primary anastomosis [3]. Resection and primary anastomosis when correctly indicated, and in the hands of an expert surgeon, gives complications and mortality rates similar to the staged surgical procedure, yet gives a better life quality [4]. In patients requiring emergency colonic resection, intraoperative antegrade colon lavage with primary anastomosis, as described by Dudley in 1983, represents a safe alternative to the staged procedure, achieving an excellent mechanical bowel toilette that allows a safe anastomosis and avoids the disadvantages associated with the multiple staged operations [5]. Large bowel obstruction is due to colorectal carcinoma in $90 \%$ of cases. The optimal management of obstructing left colonic carcinoma still remains a controversial issue. In cases of obstructing left colorectal cancer, an experienced skilled surgeon can perform one stage resection anastomosis on patients with good general condition [6]. Emergency primary anastomosis in left-sided disease can be performed with a low morbidity and mortality in selected patients, even in the presence of a free perforation with diffuse peritonitis. Patients selected for staged resection are those with major comorbid disease [3].

Primary resection and anastomosis without a protective stoma have become the treatment of choice in uncomplicated diverticulitis. Primary resection and anastomosis may also be performed for perforation with localized pericolic or pelvic abscess. A single stage procedure is associated with a decreased hospital stay, and, also has lower mortality and morbidity compared with two stage and three stage procedures [7]. A grading system for the degree of perforation associated with diverticulitis has been revised by Hinchey et al. Stage I involves diverticulitis associated with pericolic abscess, stage II involves diverticulitis associated with distant abscess (retroperitoneal or pelvic), stage III involves diverticulitis associated with purulent peritonitis, and as to stage IV it involves diverticulitis associated with fecal peritonitis [8]. Primary resection with intraoperative colonic lavage compares favorably with Hartmann's procedure for diffuse purulent peritonitis in complicated diverticulitis. Thus, primary resection with intraoperative colonic lavage should be an alternative to Hartmann's procedure in stercoral peritonitis [9].

\section{Patients}

Twenty-six patients have been included in the current study. All patients were left-sided colonic emergencies presenting at Beni-Suef University Hospital during the period between January 2016 and July 2017. All patients were admitted as emergency cases, subjected to detailed history, physical examination and laboratory and radiological examinations. Resuscitation, nasogastric decompression, correction of any abnormality and evaluation of any associated comorbidity were all undergone. Computed tomography was done selectively to confirm the diagnosis in equivocal cases.

Patients were separated into two main clinical patterns. Obstruction was the main presentation to the left-sided colonic emergencies below the splenic flexure, while perforation or leak was the presentation of the other clinical pattern. It was defined as localized if there was a pericolic abscess, pelvic abscess or retroperitoneal collection (Hinchey I \& II). It was defined as free if penumoperitoneum was evident on the abdominal x-ray film or if the feculent intra-peritoneal content was observed at operative exploration (Hinchey III \& IV).

The research got approval from the ethical committee of our surgery department than got approval of the ethical committee of the Bani - Suef faculty of medicine. An informed consent is taken form every patient explaining the intervention and the other alternatives. 


\section{Methods}

\section{Operative procedures}

I. Bowel decompression was done once the abdomen has been entered, irrespective of the site of the lesion. The caecum was inspected to make sure a perforation has neither taken place nor was imminent, and a large Foley catheter was placed through the appendix stump. This was done in cases where the caecum was not hugely distended, and in cases where it was that a wide needle was inserted in a valvular manner proximal to the lesion to deflate the colon. This should be superficial to the fluid present in the colon to guard against needle obstruction. Dissection was performed in the majority of patients by bipolar vascular sealing devices (ligature device). Vessels were controlled with a bipolar vascular sealing device or metallic clips intra-corporeally in most circumstances.

II. Dealing with the lesion, with a closure of the distal end with the straight stapler, and extraction of the specimen through a left iliac incision, with the delivery of the proximal cut bowel.

III. On table orthograde bowel lavage: A long length of pre-sterilized anesthetics scavenging tubing was attached very firmly to the proximal cut end. Normal saline was warmed to body temperature and then irrigated into the proximal colon through the Foley catheter.

IV. Cleansing of the distal segment: A proctoscope was passed into the anal canal and through it, a large Foley catheter was inserted. Normal saline was introduced through the Foley catheter to wash the lower segment.

V. Primary anastomosis was done using the circular stapler (Figures 1-7).
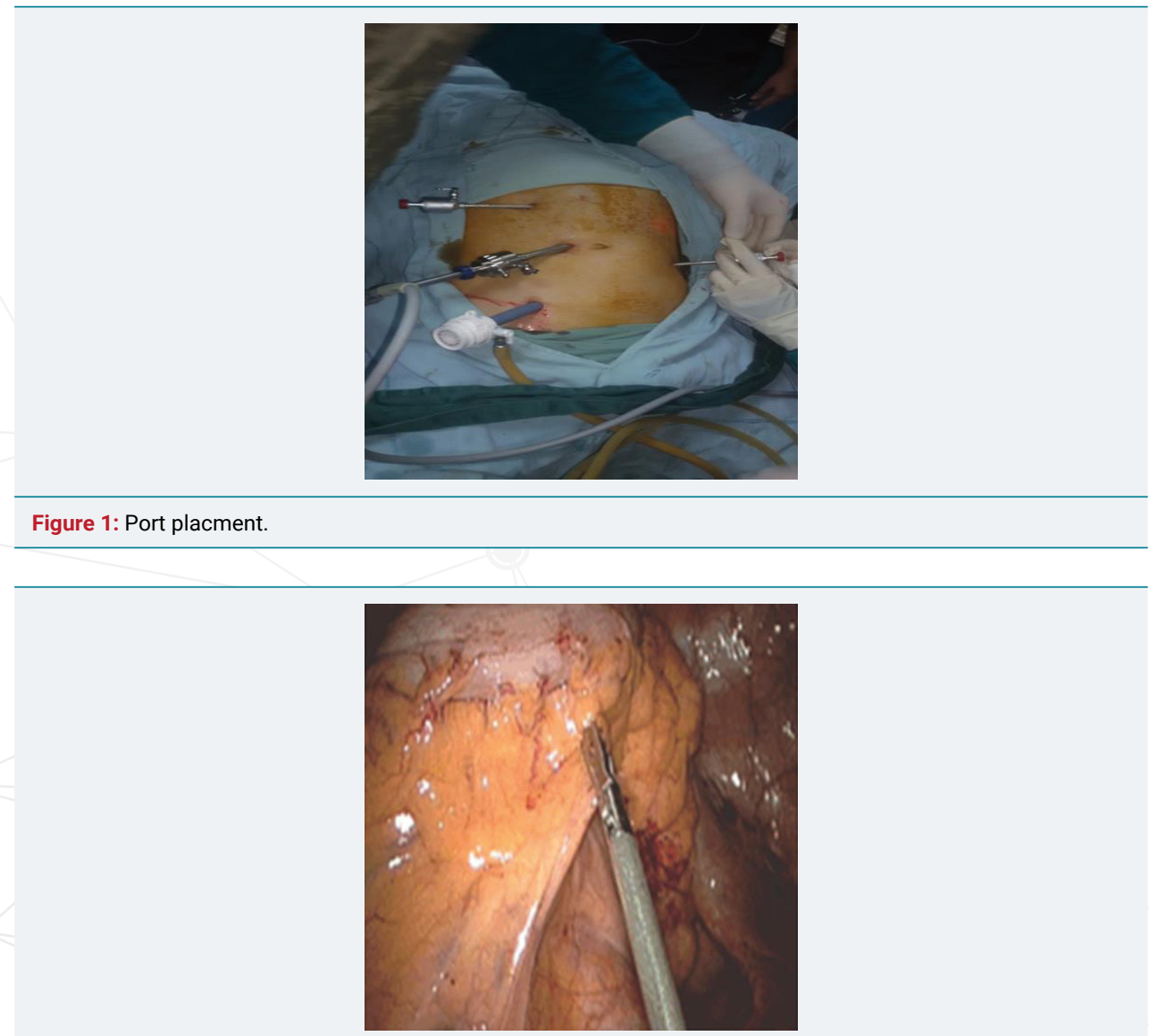

Figure 2: Dissection of the sigmoid colon. 


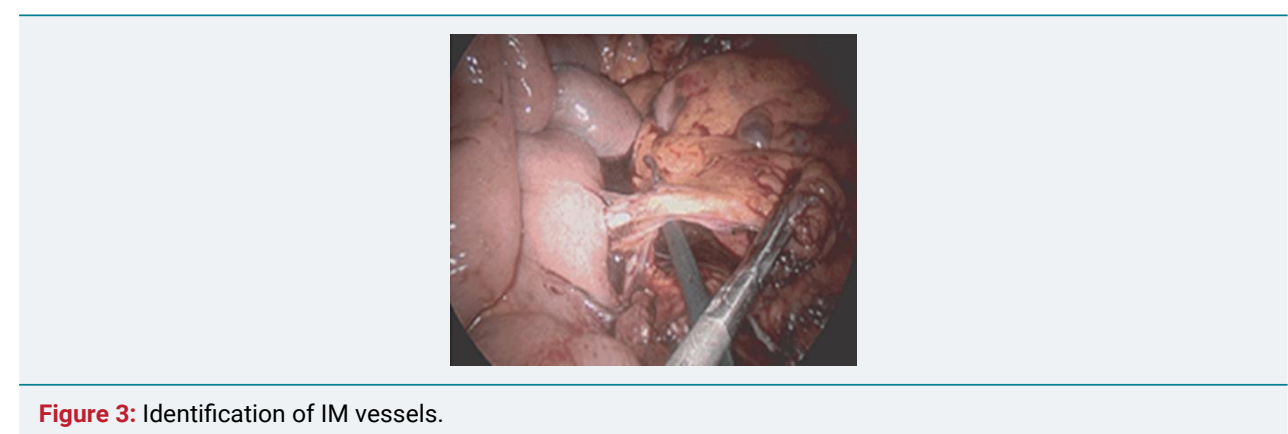

Figure 3: Identification of IM vessels.

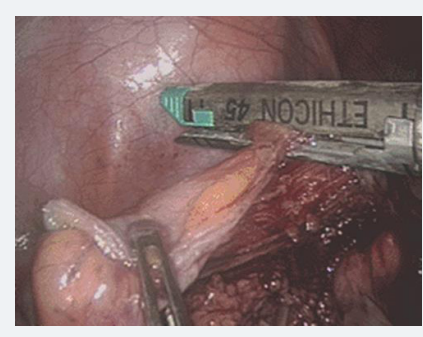

Figure 4: Staplling with linear stapler.

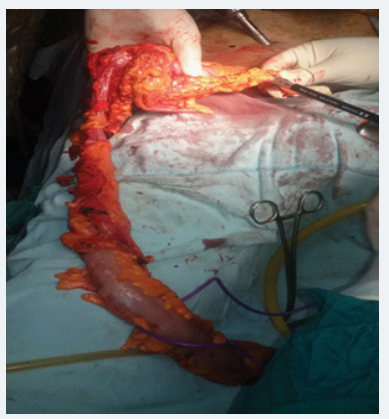

Figure 5: Delivary of the speciemen.

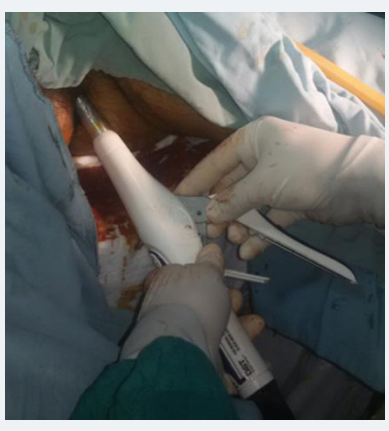

Figure 6: Anastomosis with circular stapler

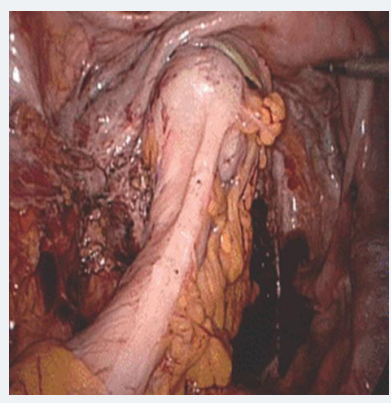

Figure 7: Leak test. 


\section{Results}

This study was conducted on 26 patients. Their age ranged from 32 years to 76 years. They were divided into groups according to operative data and histopathological examinations. The malignant group was 12 (46\%) patients. The diverticulitis group was composed of $12(46 \%)$ patients. The third group was composed of two (8\%) patients with sigmoid volvulus (Table 1).

There were 16 (62\%) patients presenting with a clinical picture of acute intestinal obstruction, two of which had sigmoid volvulus, three had an obstructed sigmoid mass, one had an obstructed rectosigmoid mass, eight had an obstructing mass in the descending colon and two had a diverticular obstruction without any peritoneal soiling. All diagnoses were confirmed histopathologically (Table 2).

The perforation cases were 10 (38\%), all of which presented with a picture of acute abdomen. 7 perforation cases had local peritonitis, and another 3 had free perforations. Table 3 All 10 cases had complicated diverticulitis. Regarding the complications, in the obstruction group, there was one (6\%) with a minimal leak which stopped on conservative treatment. Meanwhile, regarding the complications in the perforation group, there were two $(20 \%)$ leaks, one of which was with local peritonitis which improved on conservative treatment, and the other case necessitated conversion to Hartmann. The mean operative time was $185 \min (160$ - 245). The LOS was 12 days (10-18). The incidence of a leak was one in the obstruction group and two in the perforation group.

The redo incidence was one in the perforation group.

\section{Discussion}

To date, the operative strategy for left-sided large bowel obstruction remains controversial. Taking in consideration that a safe and definitive single-staged operation that avoids a colostomy, would definitely be in the patient's best interest, every effort should thus be done to perform a primary anastomosis [10]. Once obstruction and perforation were considered as absolute contraindications to primary resection and anastomosis, yet, the paradigms in the surgical management of obstruction and perforation of the left colon are changing. In the older age group, left-sided colonic emergency cases usually present with many comorbid diseases [11].

Left-sided colonic emergencies due to complicated diverticulitis comprised $46 \%$ of all emergencies, while $46 \%$ left-sided colonic emergencies were due to complicated malignant disease of the left side, and $8 \%$ of the emergencies were due to sigmoid volvulus. Meanwhile, Meyer et al. [16], reported emergencies which were due to complicated diverticular disease in $33.4 \%$ of cases, and emergencies which were due to cancer left side in $66.6 \%$ of cases.

In the current study, obstruction comprised $62 \%$ (16 cases) of left-sided emergencies, while perforation comprised 38\% (10 cases) of left-sided emergencies, of which seven cases $(70 \%)$ were focal and three cases $(30 \%)$ were a free perforation.

\begin{tabular}{|c|c|c|c|c|c|}
\hline \multicolumn{3}{|c|}{ Malignant } & \multicolumn{2}{|c|}{ Diverticulitis } & volvulos \\
\hline \multicolumn{3}{|c|}{12} & \multicolumn{2}{|c|}{12} & 2 \\
\hline \multicolumn{6}{|c|}{ Table 2: Patients with obstruction. } \\
\hline Total & Volvulos & Sigmoid mass & Rectosigmoid mass & Descending colon mass & Diverticuler obstruction \\
\hline 16 & 2 & 3 & 1 & 8 & 2 \\
\hline \multicolumn{6}{|c|}{ Table 3: Patients with perforations. } \\
\hline \multicolumn{2}{|c|}{ Total } & \multirow{2}{*}{\multicolumn{2}{|c|}{$\begin{array}{c}\text { Local peritonitis } \\
7\end{array}$}} & \multicolumn{2}{|c|}{ Free peritonitis } \\
\hline \multicolumn{2}{|r|}{10} & & & \multicolumn{2}{|r|}{3} \\
\hline
\end{tabular}


Also, in the current study, complicated diverticulitis represented $46 \%$ of left-sided colonic emergencies, while its incidence was $33.4 \%$ in the study of Meyer et al. [16]. Meyer et al., also reported that $44.4 \%$ of cases in their study had a local perforation, $22.2 \%$ of cases had free perforation and $33.3 \%$ of cases had obstruction by the inflammatory process. Meanwhile, in our current study, $17 \%$ (2 cases) were due to obstruction, 58\% (7 cases) were due to local perforation (Hinchy I, II) and 25\% (3 cases) had a free perforation (Hinchy III, IV). Trillo et al. [17], reported $76.5 \%$ of cases were due to perforation, $15.7 \%$ of cases were due to obstruction and $7 \%$ of cases were due to hemorrhage, which was not encountered within our current study.

From the practical point of view, left-sided colonic emergencies should be classified as perforating or obstructive. All the same, in many situations of this current study, it was difficult to give an accurate diagnosis through the conventional preoperative diagnostic tools, and even by computed tomography. This was most obvious and pronounced in diverticular obstruction, which mimics to a great extent malignancy. This condition called for a need for histopathological examination to do this differentiation. Thus, the patients were accordingly classified into two main groups, an obstruction group which was compromised of 16 cases (62\%) and a perforation group which was compromised of 10 cases (38\%). This pattern is almost equivocal to that of Meyer et al. [16], who reported that the incidence of obstruction cases was $72.3 \%$, and incidence of perforation cases was $27.7 \%$. Still, Biondo et al. (18), reported an equivocal incidence of $45 \%$ peritonitis cases and $55 \%$ of obstruction cases. On the other hand, our study showed that $87.5 \%$ of obstruction cases was due to non-diverticular causes and $12.5 \%$ of the obstruction cases were due to diverticular complications. These findings were similar to those of Meyer et al. [16], who reported an $84.5 \%$ incidence and $15.3 \%$ incidence respectively.

Anastomotic leak was recorded clinically in 3 cases (11.5\%). One anastomotic leak was in the obstruction group of patients, and it was a minimal leak that stopped on conservative treatment. Two anastomotic leaks were in the perforation group of patients, one of which was with the local perforation group and did well on conservative treatment, while the other was with the free perforation group and necessitated conversion to Hartmann.

Some coworkers stated that even resection and primary anastomosis can be performed safely without mechanical bowel preparation in sigmoid volvulus. Such a procedure has the merit of being a shorter and simpler procedure to perform, without any increasing morbidity or mortality [19]. Still, primary resection and anastomosis with manual decompression seem to be the procedure of choice [20].

Due to all the above-mentioned reasons, laparoscopic surgery has become the goldstandard procedure over the past decade. However, an increasing number of patients are still treated by sigmoidectomy and primary anastomosis, or by laparoscopic peritoneal lavage alone [21]. In addition to equivalent oncologic outcomes, multiple clinical trials have consistently shown lower peri-operative mortality rates. Multiple clinical trials have also shown fewer wound complications, less blood loss and reduced postoperative pain scores with a reduction in narcotic requirements after laparoscopic surgery. In spite of early concerns over port-site metastasis, cancer recurrence in wounds is reported to be similar to the $0-1 \%$ rates which are reported in open surgery. As laparoscopic lavage was not superior to sigmoidectomy, with regard to long-term major morbidity and mortality, other strategies such as laparoscopic sigmoidectomy need to be investigated [22]. Lately, the laparoscopic approach for generalized peritonitis is gaining acceptance for an increasing number of indications including cholecystitis, appendicitis, perforated peptic ulcer and small bowel obstruction [23]. Still, many surgeons regard general peritonitis, and especially fecal peritonitis, as a contraindication for a laparoscopic approach. This belief is related to a hypothetical risk of increased bacteremia and hypercapnia resulting from the pressure of the 
pneumoperitoneum [24]. Such a theory has neither been verified nor invalidated, but the experience gained with laparoscopic treatment in abdominal sepsis of various causes does not back this hypothesis [25].

\section{Conclusion}

Emergency laparoscopic left-sided colonic resection and primary anastomosis can be performed with a low morbidity but with caution in the presence of a free perforation with peritonitis, although it is linked with a high cost.

\section{References}

1. Klarenbeek BR1, Veenhof AA, Bergamaschi R, van der Peet DL, van den Broek WT, et al. Laparoscopic sigmoid resection for diverticulitis decreases major morbidity rates: a randomized control trial: short-term results of the Sigma Trial. Ann Surg. 2009; 249: 39-44. Ref.: https://goo.gl/FKdmHj

2. Karthik S, Augustine AJ, Shibumon MM, Pai MV. Analysis of laparoscopic port-site complications: A descriptive study. Journal of Minimal Access Surgery. 2013; 9: 59- 64. Ref.: https://goo.gl/KStoBQ

3. Zorcolo L, Covotta L, Carlomango N, Bartolo DC. Safety of primary anastomosis in emergency Colorectal surgery. Colorectal Dis. 2003; 5: 262-269. Ref.: https://goo.gl/rxYG86

4. Capasso L1, D'Ambrosio R, Sgueglia S, Carfora E, Casale LS, et al. Emergency surgery for neoplastic Left colon obstruction. Ann Ital Chir. 2004; 75: 465-470. Ref.: https://goo.gl/g6xMng

5. Seidenschnur AM and Beck K. Preoperative lavage and primary anastomosis in acute left-sided colon ileus. Vgeskr Laeger. 2001; 163: 2489-2492. Ref.: https://goo.gl/5NVekS

6. Pisanu A, Piu S, Altana ML, Vccheddu A. One-stage treatment of obstructing Colorectal Cancer. Chir Ital. 2002; 54: 267-274. Ref.: https://goo.gl/EitVHi

7. Sarin S and Boulos PB. Evaluation of current surgical management of the acute inflammatory diverticular disease. Ann R Coll Surg Engl. 1991; 73: 278-287. Ref.: https://goo.gl/WihXj8

8. Hinchey EF, Schaal PG, Richard GK. Treatment of perforated diverticular disease of the colon. Adv Surg. 1978; 12: 85-109. Ref.: https://goo.gl/3fb5UX

9. Regenet N1, Pessaux P, Hennekinne S, Lermite E, Tuech JJ, et al. Primary anastomosis after intraoperative colonic lavage VS. Hartmann's procedure in peritonitis complicating diverticular disease of the colon. Int J Colorectal Dis. 2003; 18: 503-507. Ref.: https://goo.gl/XPuoBP

10. Turan M1, Ok E, Sen M, Koyuncu A, Aydin C, et al. A simplified operative technique for single staged resection of left-sided colon obstruction. Surg Today. 2002; 32: 959-964. Ref.: https://goo.gl/Te3UHm

11. Goyal A, Schein M. Survey of US gastrointestinal surgeons. Arch Surg. 2000; 135: 558-563.

12. Celi $S$, Parisi $A$, Maccarone $P$, Alberti $A$, Littori $F$, et al. Surgical treatment of acute colonic diverticulitis. Ann Ital Chir. 2001; 72: 437-441. Ref.: https://goo.gl/a8HDxg

13. Vinas-Salas J, Villalba-Acosta J, Scaramucci M et al. Complication of colonic diverticular disease. Rev Esp Enferm Dig. 2001; 93: 649-658.

14. Bahadursingh AM1, Virgo KS, Kaminski DL, Longo WE. Spectrum of disease and outcome of the complicated diverticular disease. Am J Surg. 2003; 186: 696-701. Ref.: https://goo.gl/fxrjms

15. Chiappa A1, Zbar A, Biella F, Staudacher C. One-stage resection and primary anastomosis following acute obstruction of the left colon. Am Surg. 2000; 66: 619-622. Ref.: https://goo.gl/iJWbcu

16. Meyer C, Rohr S, Iderne A, Tiberio G, Bourtoul C. The value of pre-operative colonic lavage in urgent colonic surgery. J Chir (Paris). 1997; 134: 271-274. https://goo.gl/3psPjs

17. Trilloc M, Paris MF, Brennan JT. Primary anastomosis in the treatment of acute disease of the unprepared left colon. Am Surg. 1998; 64: 824-825. Ref.: https://goo.gl/Z5w8Q9

18. Biondo $\mathrm{S}$, Jaurrieta $\mathrm{E}$, Jorba $\mathrm{R}$ et al. Intra-operative colonic lavage and primary anastomosis in peritonitis and obstruction. Br J Surg. 2001; 88: 1419-1422.

19. Khan M, Ullah S, Asad M UI. Primary anastomosis in the management of acute sigmoid volvulus without colonic lavage. JMPI. 2007; 21: 305-308. Ref.: https://goo.gl/x4Z24f

20. Ansaloni L1, Andersson RE, Bazzoli F, Catena F, Cennamo V, et al. Guidelenines in the management of obstructing cancer of the left colon: consensus conference of the world society of emergency surgery (WSES) and peritoneum and surgery (PnS) society. World J Emerg Surg. 2010; 5: 29. Ref.: https://goo.gl/n2h5bg 
21. Rogers AC, Collins D, O'Sullivan GC, Winter DC. Laparoscopic lavage for perforated diverticulitis: a population analysis. Dis Colon Rectum. 2012; 55: 932-938. Ref.: https://goo.gl/ryhevS

22. Vennix S, Musters GD, Mulder IM, Swank HA, Consten EC, et al. Ladies Trial Collaborators: Laparoscopic peritoneal lavage or sigmoidectomy for perforated diverticulitis with purulent peritonitis: a multicentre, parallel-group, randomised, open-label trial. Lancet 2015; 386: 1269-1277. Ref.: https://goo.gl/PKQhd4

23. Sartelli M, Viale $P$, Catena F, Ansaloni L, Moore E, et al. 2013 WSES guidelines for management of intra-abdominal infections. World J Emerg Surg 2013; 8: 3. Ref.: https://goo.gl/EcvbwZ

24. Neudecker J, Sauerland S, Neugebauer E, Bergamaschi R, Bonjer HJ, et al. The European Association for endoscopic surgery clinical practice guideline on the pneumoperitoneum for laparoscopic surgery. Surg Endosc 2002; 16:1121-1143. Ref.: https://goo.gl/1jWHco

25. Veldkamp R, Kuhry E, Hop WC, Jeekel J, Kazemier G, Bonjer HJ, et al. Laparoscopic surgery versus open surgery for colon cancer: short-term outcomes of a randomized trial. Lancet Oncol. 2005; 6: 477-484. Ref.: https://goo.gl/8sv1vL 